\title{
Liberation of Protoplasts from the Mycelium of Phytophthora
}

\author{
By S. BARTNICKI-GARCIA AND ELEANOR LIPPMAN \\ Department of Plant Pathology University of California \\ Riverside, California, U.S.A.
}

(Received 23 September 1965)

\begin{abstract}
SUMMARY
Spherical protoplast-like bodies were released from the mycelia of Phytophthora cinnamomi and $\boldsymbol{P}$. parasitica on digestion of their hyphal walls with an extracellular enzyme preparation from Streptomyces sp. in media of appropriate osmotic pressure. Protoplast liberation was observed when using as osmotic stabilizer either sucrose or mannitol $(0.2 \mathrm{M}-0.8 \mathrm{M})$; maximum response at about $0.4 \mathrm{M}-0.6 \mathrm{M}$. Although hyphal wall digestion was always extensive, the amount of protoplast release varied widely under seemingly similar conditions. Protoplasts were liberated from the phytophthora mycelium by two mechanisms: bud-like emergence in which cytoplasm was squeezed through a small pore in the wall usually located at or near a hyphal apex; or intercalary hyphal swelling, which consisted of the swelling and rounding off of short hyphal segments whose walls became progressively thinner until they were no longer visible. Both types of protoplast were osmotically sensitive and disintegrated upon dilution of the suspending media.
\end{abstract}

\section{INTRODUCTION}

A crude extracellular enzyme preparation from Streptomyces sp. strain QMB 814 (Reese, Smakula \& Perlin, 1959) can almost completely dissolve the hyphal walls of Phytophthora cinnamomi (Bartnicki-Garcia \& Lippman, to be published). The preparation effectively digested isolated purified hyphal walls as well as the walls of living mycelium. The lytic action is believed to be chiefly due to $\beta$-glucanases which cleave the major components of the wall, namely cellulose and other glucan(s), to soluble carbohydrate molecules of a wide range of sizes. The present work was prompted by the availability of this enzyme preparation which is capable of rapidly lysing the hyphal walls of phytophthora and a desire to prepare cellular forms of phytophthora devoid of cell walls which could be used for studies of cellwall biosynthesis. The release of seemingly wall-free protoplast-like bodies from the mycelia of $\boldsymbol{P}$. cinnamomi and $\boldsymbol{P}$. parasitica, described here, was attained by digesting hyphal walls of living mycelia in an osmotically favourable environment.

\section{METHODS}

The strains of Phytophthora cinnamomi and $\boldsymbol{P}$. parasitica, and the culture media used were as described by Bartnicki-Garcia (1966). Protoplast release was followed under a bright-field Reichert Zetopan microscope equipped with a Polaroid camera. Sterile micro-chambers were improvised with ordinary microscope slides and coverslips. A square frame of silicon lubricant (Dow Corning, high vaccum grease), the 
size of a coverslip, was applied to the centre of a microscope slide. After the slide was sterilized in the autoclave, a small piece of mycelium was placed on its centre and excess liquid removed with a capillary pipette. The mycelium was rinsed once with a drop of enzyme solution. A fresh drop was then added, and a sterile coverslip pressed against the silicon grease to form a liquid-tight chamber. Incubations were at room temperature $\left(21-26^{\circ}\right)$.

Mycelium for incubation in the micro-chambers was prepared by the following technique. A small portion of a mycelial mat from a 7-10-day stationary culture in liquid V-8 juice medium (Campbell Soup Co.) was homogenized at slow speed in $15 \mathrm{ml}$. of fresh V-8 solution in a Sorvall Omni-mixer for $3 \mathrm{~min}$. The resulting suspension of mycelial fragments was poured into a Petri dish and incubated for 1 or sometimes 2 days, at $27^{\circ}$. Thus were obtained small actively growing pieces of mycelium which could be transferred intact to the micro-chambers with a Pasteur pipette.

The streptomyces enzyme preparation was kindly given by $\mathrm{Dr}$ E. T. Reese (U.S. Army, Quartermaster Research and Engineering Centre, Natick, Massachusetts). Enzyme solutions containing $120 \mathrm{Cx}$ cellulase units/ml. were made in $0.05 \mathrm{M}$ citrate buffer (sodium citrate + citric acid; $\mathrm{pH} \mathrm{5.8)}$ ) or in 0.1 M-phosphate buffer $\left(\mathrm{K}_{2} \mathrm{HPO}_{4}+\mathrm{KH}_{2} \mathrm{PO}_{4} ; \mathrm{pH} \mathrm{6 \cdot 8}\right)$. Buffers were adjusted to various concentractions of sucrose (A.R.), mannitol (commercial grade) or $\mathrm{KCl}$ (A.R.) to increase the osmotic pressure. Enzyme solutions were sterilized through Millipore filters.

\section{RESULTS}

By providing adequate osmotic protection during the enzymic hydrolysis of living mycelial walls of Phytophthora cinnamomi or $\boldsymbol{P}$. parasitica, the formation of large spherical protoplast-like bodies was commonly observed (Pls. 1, 2). Protoplasts were liberated in digestion media which contained mannitol, sucrose or $\mathrm{KCl}$ as osmotic regulators in citrate or phosphate buffers. Protoplasts appeared in sucrose or mannitol concentrations ranging from $0.2 \mathrm{M}$ to $0.8 \mathrm{M}$ with better responses at about $0.4 \mathrm{M}$ to $0.6 \mathrm{M}$. Potassium chloride was similarly effective, except at $0.8 \mathrm{M}$ at which concentration no protoplasts were released. Without osmotic stabilizers no protoplasts were released; instead, amorphous masses of protoplasm were extruded, mainly through the burst tips of some hyphae.

Autolysis of phytophthora mycelium was not detected even after prolonged incubation in the micro-chambers. Thus, control specimens containing no Streptomyces enzyme, showed no sign of hyphal wall degradation, nor any evidence of protoplasm release by either amorphous discharge or protoplast liberation.

Liberated mycelium-protoplasts were usually spherical, but occasionally irregularly bulged bodies were also observed (Pl. 2, fig. 6). Protoplast size ranged from 10 to $40 \mu$ and was considerably greater than the diameter of the parental hyphae. The internal morphology of the protoplasts varied considerably, reflecting in this respect the variability of cytoplasmic structure of the hyphae from which they derived.

From both phytophthora species, protoplasts appeared by two distinct processes, namely a bud-like emergence or intercalary hyphal swelling. Early protoplasts, which under optimum conditions could begin to emerge after incubation for $1 \mathrm{hr}$, were released even before the walls showed any visible sign of digestion 
and always emerged in a bud-like manner, i.e. a variable amount of protoplasm was squeezed through a small not readily visible pore in the wall, forming on the outside a growing spherical body. The final size and time of detachment of protoplasts varied greatly. Sometimes more than one protoplast was formed on a single hypha from what appeared to be a continuous mass of discharging protoplasm ( $\mathrm{Pl}$. 2, fig. 7). The liberation of large protoplasts required the mobilization of protoplasm from relatively distant hyphal regions. Thus it was calculated (neglecting volume changes due to osmotic pressure differences) that a protoplast $40 \mu$ in diameter contained protoplasm equivalent to a $1185 \mu$ length of hypha of average diameter $6 \mu$.

In a more advanced digestion stage, i.e. after incubation for $12 \mathrm{hr}$, when the hyphal walls were perceptibily thinner, the appearance by intercalary swelling was more common. This consisted of the swelling and rounding off of short hyphal segments whose walls became progressively thinner; protoplasm from adjacent hyphal regions emptied into the swellings which assumed a spherical form. Several such swellings and their resulting protoplast-like bodies could form from a single hypha (Pl. 2, fig. 8). Careful observation revealed that intercalary protoplasts, derived from one hypha, sometimes remained connected in a chain by a barely visible thread, presumably the collapsed remnant of the hyphal wall. No cell wall was readily evident on the protoplasts themselves.

Protoplasts were stable and retained their external morphology for several days when kept in the sealed micro-chambers where they had been liberated. There were, however, marked internal changes, such as the cytoplasm becoming coarsely granulated.

The osmotic stability of the protoplasts was tested by running water through the micro-chamber (silicon grease omitted). Addition of distilled water caused the protoplasts to swell slightly and to burst with disintegration of their membrane, which then ceased to be visible. Concomitant with bursting, a spherical vesicle, about the original size of the protoplast, was frequently formed. Conceivably these vesicles represent swollen cytoplasmic vacuoles and, characteristically, protoplast debris remained attached to them from without (Pl. 2, figs. 9, 10).

The extent of protoplast liberation, from one experiment to the next under seemingly similar conditions, was widely variable. However, duplicates within one experiment were almost always in agreement. In some rare instances, there was observed a massive liberation of protoplasts as illustrated in Pl. 2, fig. 5; on other occasions, however, complete failure to release protoplasts was encountered. Intriguingly, hyphal walls seemed to have been extensively digested in both cases. The usual degree of hyphal wall digestion of phytophthora can be appreciated by comparing figs. 1 and 2 of $\mathrm{Pl} .1$.

Protoplasm was not always discharged as protoplasts even under favourable osmotic conditions. Thus in a given preparation, obviously suitable for protoplast formation since many such bodies were actually formed, certain hyphae would discharge their cytoplasm into amorphous masses devoid of a limiting membrane, while simultaneously neighbouring hyphae gave normal protoplasts. On one occasion cytoplasm was seen to discharge amorphously through the same pore from which protoplast had emerged immediately before. On comparing mycelial pieces grown for 1 or $\mathbf{2}$ days no consistent response was obtained indicative of an optimum age for protoplast release. 
Mycelial pieces under digestion were still capable of further growth despite concomitant extensive wall lysis. This renewed growth was especially noticed after incubation for about $24 \mathrm{hr}$ with enzyme solutions containing $0.2 \mathrm{M}$ - to $0.6 \mathrm{M}$ sucrose; it consisted of long branched hyphae with walls of normal appearance radially protruding around the periphery of the extensively digested initial mycelial piece. That the enzyme preparation was active during the growth of these new hyphae may be deduced from the fact that, on continued incubation for another day their walls also were lysed, yielding a second crop of intercalary protoplasts. This alternating sequence of digestion and growth suggests that the hyphal walls of Phytophthora vary in their susceptibility to enzymic attack.

No significant differences in protoplast liberation or behaviour were detected between Phytophthora cinnamomi and $\boldsymbol{P}$. parasitica except that the latter seemed to liberate protoplasts somewhat more readily.

\section{DISCUSSION}

Protoplast liberation in filamentous fungi was first observed in Neurospora crassa (Emerson \& Emerson, 1958; Bachmann \& Bonner, 1959) by the action of a hemicellulase preparation of snail digestive juice on its mycelial or conidial walls. Subsequently, Villanueva and co-workers released protoplasts and like structures from other chitinous filamentous fungi by using snail juice (Rodriguez-Aguirre \& Villanueva, 1962; Garcia Acha \& Villanueva, 1963), or a lytic preparation from a streptomyces (Garcia Acha \& Villanueva, 1963; Rodriguez-Aguirre, Garcia Acha $\&$ Villanueva, 1964). The present communication, we believe, is the first to describe the artificial release of protoplasts from a fungus with cellulosic walls.

A set of requirements specified by Brenner $e$ t al. (1958) to define a bacterial protoplast could also be extended to fungal protoplasts. The main criterion is the complete absence of cell wall from osmotically sensitive spherical protoplasts. The spherical bodies released from phytophthora mycelia were osmotically sensitive and appeared, under the microscope, to lack most, if not all, of the original cell wall; however, definite evidence for absence of cell wall is not available. Whether or not the 'protoplasts' from phytophthora mycelia are entirely devoid of the original cell wall may be a question related to their genesis. Thus protoplasts which arise by emergence through a pore are probably entirely deprived of cell wall; on the other hand, it is possible that some undigested wall remained attached to the membrane of protoplasts formed by swelling of hyphal sections. In support of this view, studies on the digestion of isolated hyphal walls of phytophthora (Bartnicki-Garcia \& Lippman; to be published) have indicated that a small portion of the wall was not dissolved by the streptomyces enzyme preparation even after digestion for $24 \mathrm{hr}$ at $50^{\circ}$.

The phytophthora mycelium is coenocytic; therefore protoplast extrusion may involve the artificial separation of a continuous protoplasm to form spherical units at the time of liberation; see, for example, the simultaneous emergence of two protoplasts through separate pores, but both arising from the same protoplasmic mass (Pl. 2, fig. 7). Bachmann \& Bonner (1959) considered the protoplasts from neurospora as artifacts since even the protoplasm confined within two septa could give rise to more than one protoplast. 
Protoplast release from phytophthora mycelia was widely variable under seemingly equal conditions even though hyphal walls were always extensively digested. Factors other than wall digestion and adequate osmotic pressure must also intervene in the successful liberation of a protoplast. The extrusion of protoplasm without a limiting membrane and occurring under conditions favourable for protoplast formation might be an indication of variations in the fragility of the cytoplasmic membrane and of its failure to maintain continuity under the pressure of expulsion.

Phytophthora, like other aquatic Phycomycetes, release during their life cycles flagellated zoospores which may be regarded in some respects as natural protoplasts. Although zoospores are not quite spherical, and will withstand very low osmotic pressure without bursting, they seemingly lack a cell wall. Although the internal fine structure of phytophthora zoospores has not yet been reported, electron microscopy of thin-sectioned zoospores of other fungi (e.g. Blastocladiella emersonii; Cantino, Lovett, Leak \& Lythgoe, 1963) indicate the absence of a cell wall. Questions then arise as to whether the membrane of an artificial protoplast is of the same nature as that of a zoospore and whether phytophthora protoplasts are able to regenerate a cell wall de novo.

This investigation was supported in part by a research grant (AI 06205) from the National Institutes of Health, U.S.A.

\section{REFERENCES}

Bachmann, B. J. \& Bonner, D. M. (1959). Protoplasts from Neurospora crassa. J. Bact. 78, 550.

Bartnicki-Garcia, S. (1966). Chemistry of hyphal walls of phytophthora. J. gen. Microbiol. 42, 56.

Brenner, S., Dark, F. A., Gerhardt, P., Jeynes, M. H., Kandler, O., Keluenberger, E., Klieneberger-Nobel, E., McQuillen, K., Rubio-Huertos, M. , Salton, M. R. J., Strange, R. E., Tomcsik, J. \& Weibul,, C. (1958). Bacterial protoplasts. Nature, Lond. 181, 1713.

Cantino, E. C., LovetT, J. S., LEaK, L. V. \& LYThgok, J. (1963). The single mitochondrion, fine structure, and germination of the spore of Blastocladiella emersonii. $J$. gen. Microbiol. 31, 393.

Emerson, S. \& Emerson, M. R. (1958). Production, reproduction and reversion of protoplast-like structures in the osmotic strain of Neurospora crassa. Proc. natn. Acad. Sci., U.S.A. 44, 668.

Garcia Acha, I. \& Villanueva, J. R. (1963). Differences in the mode of action of strepzyme and Helix pomatia enzyme preparation on Trichothecium roseum spores. Nature, Lond. 200, 1231.

Reese, E. T., Smakula, E. \& Perlin, A. S. (1959). Enzymic production of cellotriose from cellulose. Archs Biochem. Biophys. 85, 171.

Rodriguez-Aguirre, M. J. \& Villanueva, J. R. (1962). Production of protoplast-like structures from various species of fungi. Nature, Lond. 196, 693.

Rodriguez-Aguirre, M. J., Garcia Acha, I. \& Villanueva, J. R. (1964). Formation of protoplasts of Fusarium culmorum by strepzyme. Antonie van Leeurenhoek, 30, 33. 


\section{EXPLANATION OF PLATES}

\section{Plate 1}

Fig. 1. Mycelium of Phytophthora cinnamomi incubated with streptomyces enzyme in phosphate 0.8 M mannitol buffer. Zero time. ( $\times$ 170.)

Fig. 2. Same as fig. 1 after incubation for $68 \mathrm{hr} .(\times 170$.

Fig. 3. Protoplast of $P$. cinnamomi released in phosphate $0.6 \mathrm{M}-$ mannitol buffer. $(\times 825$.

Fig. 4. Protoplasts of $P$. parasitica released in phosphate $0.6 \mathrm{M}$-mannitol buffer. $(\times 825$.)

\section{Plate 2}

Fig. 5. Abundant release of protoplasts from mycelium of $P$. cinnamomi after digestion for 1 day with Streptomyces enzyme in phosphate $0.6 \mathrm{M}$-mannitol buffer. $(\times 115$. $)$

Fig. 6. Irregularly shaped protoplast-like bodies from $P$. cinnamomi produced in same slide as that of Pl. 1, fig. 3. ( $\times 710$.)

Fig. 7. Simultaneous release of two protoplasts from a hyphal tip of $P$. parasitica after digestion for $2 \mathrm{hr}$ with Streptomyces enzyme in phosphate 0.6 M-mannitol buffer. $(\times 1140$.)

Fig. 8. Chain of protoplasts (right) formed by intercalary swelling of a hypha from $P$. cinnamomi digested with Streptomyces enzyme in phosphate $0.6 \mathrm{M}$-mannitol buffer for 1 day. $(\times 115$.

Figs. 9, 10. Protoplasts of $P$. cinnamomi osmotically lysed with distilled water. $(\times 670$. $)$ 
Journal of General Microbiology, Vol. 42, No. 3

Plate 1
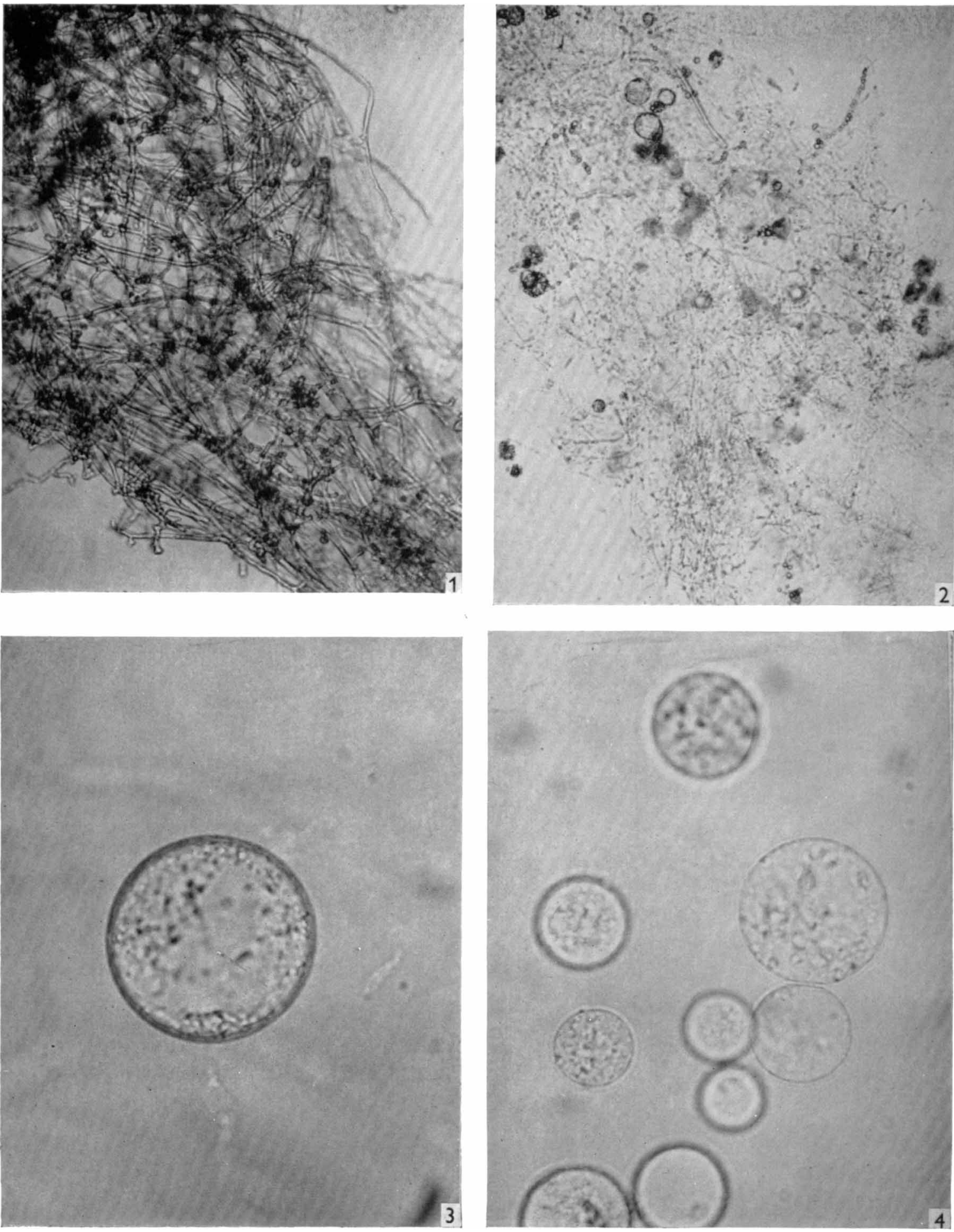

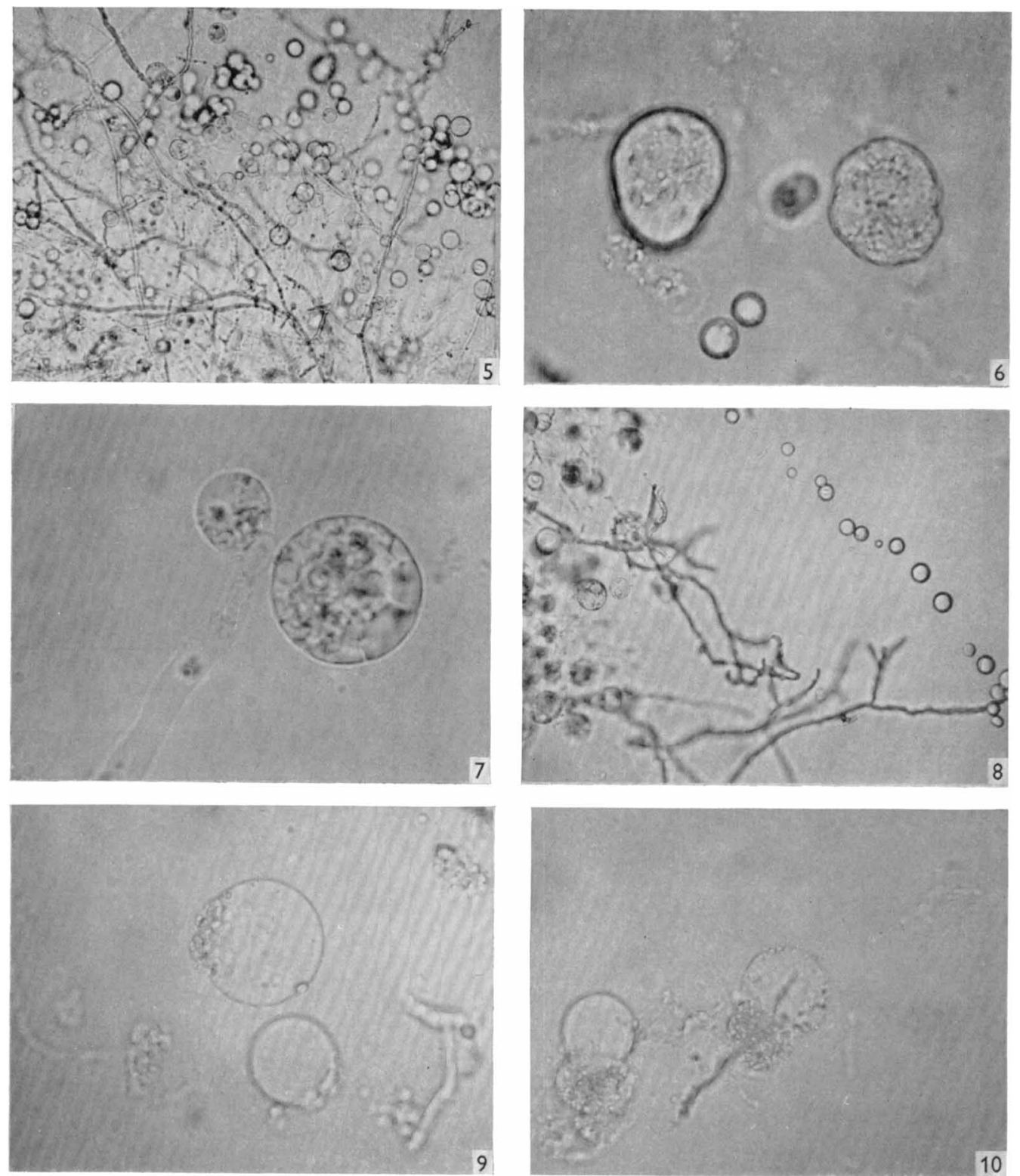